\title{
A Review of Platelet-Rich Plasma: History, Biology, Mechanism of Action, and Classification
}

\author{
Rubina Alves Ramon Grimalt \\ Department of Dermatology, Universitat International Catalunya, Barcelona, Spain
}

\section{Keywords}

Platelet-rich plasma · Plasma · Autologous therapy · Biology . Mechanism of action

\begin{abstract}
Platelet-rich plasma (PRP) is currently used in different medical fields. The interest in the application of PRP in dermatology has recently increased. It is being used in several different applications as in tissue regeneration, wound healing, scar revision, skin rejuvenating effects, and alopecia. PRP is a biological product defined as a portion of the plasma fraction of autologous blood with a platelet concentration above the baseline. It is obtained from the blood of patients collected before centrifugation. The knowledge of the biology, mechanism of action, and classification of the PRP should help clinicians better understand this new therapy and to easily sort and interpret the data available in the literature regarding PRP. In this review, we try to provide useful information for a better understanding of what should and should not be treated with PRP.

(c) 2017 S. Karger AG, Basel
\end{abstract}

\section{History of Platelet-Rich Plasma}

Platelet-rich plasma (PRP) is also known as plateletrich growth factors (GFs), platelet-rich fibrin (PRF) matrix, PRF, and platelet concentrate.

The concept and description of PRP started in the field of hematology [1]. Hematologists created the term PRP in the 1970s in order to describe the plasma with a platelet count above that of peripheral blood, which was initially used as a transfusion product to treat patients with thrombocytopenia [2].

Ten years later, PRP started to be used in maxillofacial surgery as PRF. Fibrin had the potential for adherence and homeostatic properties, and PRP with its anti-inflammatory characteristics stimulated cell proliferation [3].

Subsequently, PRP has been used predominantly in the musculoskeletal field in sports injuries. With its use in professional sportspersons, it has attracted widespread attention in the media and has been extensively used in this field [4]. Other medical fields that also use PRP are cardiac surgery, pediatric surgery, gynecology, urology, plastic surgery, and ophthalmology [5].

Rubina Alves, $\mathrm{MD}, \mathrm{PhD}$

Estrada Monumental, 364, 3F

PT-9000-100 Funchal, Madeira (Portugal)

E-Mail rubinaalves@gmail.com 
More recently, the interest in the application of PRP in dermatology; i.e., in tissue regeneration, wound healing, scar revision, skin rejuvenating effects, and alopecia, has increased [1, 6-14].

Wounds have a proinflammatory biochemical environment that impairs healing in chronic ulcers. In addition, it is characterized by a high protease activity, which decreases the effective GF concentration. PRP is used as an interesting alternative treatment for recalcitrant wounds because it is a source of GFs and consequently has mitogenic, angiogenic, and chemotactic properties [12].

In cosmetic dermatology, a study performed in vitro demonstrated that PRP can stimulate human dermal fibroblast proliferation and increase type I collagen synthesis [13]. Additionally, based on histological evidence, PRP injected in human deep dermis and immediate subdermis induces soft-tissue augmentation, activation of fibroblasts, and new collagen deposition, as well as new blood vessels and adipose tissue formation $[14,15]$.

Another application of PRP is the improvement of burn scars, postsurgical scars, and acne scars [16]. According to the few articles available, PRP alone or in combination with other techniques seems to improve the quality of the skin and leads to an increase in collagen and elastic fibers.

In 2006, PRP has started to be considered a potential therapeutic tool for promoting hair growth and has been postulated as a new therapy for alopecia, in both androgenetic alopecia and alopecia areata. Several studies have been published that refer to the positive effect PRP has on androgenetic alopecia, although a recent meta-analysis suggested the lack of randomized controlled trials [17]. As stated by the authors, controlled clinical trials are considered the best way to provide scientific evidence for a treatment and avoid potential bias when assessing efficacy [18].

\section{Platelet Biology}

All blood cells derive from a common pluripotent stem cell, which differentiates into different cell lines. Each of these cell series contains precursors that can divide and mature.

Platelets, also called thrombocytes, develop from the bone marrow. Platelets are nucleated, discoid cellular elements with different sizes and a density of approximately $2 \mu \mathrm{m}$ in diameter, the smallest density of all blood cells. The physiological count of platelets circulating in the

Platelet-Rich Plasma: A Review blood stream ranges from 150,000 to 400,000 platelets per $\mu \mathrm{L}$.

Platelets contain several secretory granules that are crucial to platelet function. There are 3 types of granules: dense granules, o-granules, and lysosomes. In each platelet there are approximately 50-80 granules, the most abundant of the 3 types of granules.

Platelets are primarily responsible for the aggregation process. The main function is to contribute to homeostasis trough 3 processes: adhesion, activation, and aggregation. During a vascular lesion, platelets are activated, and their granules release factors that promote coagulation [19].

Platelets were thought to have only hemostatic activity, although in recent years, scientific research and technology has provided a new perspective on platelets and their functions. Studies suggest that platelets contain an abundance of GFs and cytokines that can affect inflammation, angiogenesis, stem cell migration, and cell proliferation [20].

PRP is a natural source of signaling molecules, and upon activation of platelets in PRP, the P-granules are degranulated and release the GFs and cytokines that will modify the pericellular microenvironment. Some of the most important GFs released by platelets in PRP include vascular endothelial GF, fibroblast GF (FGF), platelet-derived GF, epidermal GF, hepatocyte GF, insulin-like GF 1, 2 (IGF-1, IGF-2), matrix metalloproteinases 2, 9, and interleukin $8[1,21]$.

\section{Definition}

PRP is a biological product defined as a portion of the plasma fraction of autologous blood with a platelet concentration above the baseline (before centrifugation) [22]. As such, PRP contains not only a high level of platelets but also the full complement of clotting factors, the latter typically remaining at their normal, physiologic levels [23]. It is enriched by a range of GFs, chemokines, cytokines, and other plasma proteins [4].

The PRP is obtained from the blood of patients before centrifugation. After centrifugation and according to their different density gradients, the separation of blood components (red blood cells, PRP, and platelet-poor plasma [PPP]) follows.

In PRP, besides the higher concentration of platelets, other parameters need to be taken into account, such as the presence or absence of leucocytes and activation. This will define the type of PRP used in different pathologies.

Skin Appendage Disord 2018;4:18-24 DOI: $10.1159 / 000477353$ 
There are several commercial devices available, which simplify the preparation of PRP. According to the manufacturers, PRP devices usually achieve a concentration of PRP 2-5 times the baseline concentration. Although one might think that a higher platelet count with a higher number of GFs would lead to better results, this has not been determined yet [20]. In addition, 1 study also suggests that a concentration of PRP 2.5 times above the baseline could have an inhibitory effect [24].

\section{Mechanism of Action in Alopecia}

The GFs and the bioactive molecules present in PRP promote 4 main actions in the local environment of the administration, such as proliferation, migration, cell differentiation, and angiogenesis [22, 25-28]. Various cytokines and GFs are involved in the regulation of hair morphogenesis and cycle hair growth [29].

The dermal papilla (DP) cells produce GFs such as IGF-1, FGF-7, hepatocyte growth factor, and vascular endothelial growth factor that are responsible for maintaining the hair follicle in the anagen phase of the hair cycle. Therefore, a potential target would be to upregulate these GFs within the DP cells, which lengthen the anagen phase [30].

According to a study performed by Akiyama et al. [31], epidermal growth factor and transforming growth factor are involved in regulating the growth and differentiation of bulge cells, and platelet-derived growth factor may have related functions in the interactions between the bulge and the associated tissues, starting with follicle morphogenesis [27].

Beside the GFs, the anagen phase is also activated by $\mathrm{Wnt} / \beta$-catenin/T-cell factor lymphoid enhancer [32]. In the DP cells, the activation of Wnt will lead to an accumulation of $\beta$-catenin, which, in combination with the T-cell factor lymphoid enhancer, also acts as a co-activator of transcription and promotes proliferation, survival, and angiogenesis. The DP cells then initiate the differentiation and consequently the transition from the telogen to the anagen phase [25]. $\beta$-Catenin signaling is important in human follicle development and for the hair growth cycle.

Another pathway presented in DP is the activation of extracellular signal-regulated kinase (ERK) and protein kinase B (Akt) signaling that promotes cell survival and prevents apoptosis [6].

The precise mechanism by which PRP promotes hair growth is not fully understood. To explore the possible mechanisms involved, Li et al. [6] performed a well-designed study to investigate the effects of PRP on hair growth using in vitro and in vivo models. In the in vitro model, activated PRP was applied to human DP cells obtained from normal human scalp skin. The results demonstrated that PRP increased the proliferation of human DP cells by activating ERK and Akt signaling, leading to antiapoptotic effects. PRP also increased the $\beta$-catenin activity and FGF-7 expression in DP cells. Concerning the in vivo model, mice injected with activated PRP showed a faster telogen-to-anagen transition in comparison to the control group.

Recently, Gupta and Carviel [25] also proposed a mechanism for the action of PRP on the human follicles that includes the "elicitation of the Wnt/ $\beta$-catenin, ERK, and Akt signaling pathways fostering cell survival, proliferation, and differentiation."

After GF binds with its correspondent GF receptor, the signaling necessary for its expression begins. The GF-GF receptor activates the expression of both Akt and ERK signaling. The activation of Akt will inhibit 2 pathways through phosphorylation: (1) the glycogen synthase kinase- $3 \beta$ that promotes degradation of $\beta$-catenin, and (2) Bcl-2-associated death promoter, which is responsible for inducing apoptosis. As stated by the authors, PRP might increase vascularization, prevent apoptosis, and prolong the duration of the anagen phase [27].

The main functions of the GFs presented in the PRP are detailed in Table 1.

\section{Devices to Obtain PRP}

Currently, there is a great discussion and no consensus regarding PRP preparation. PRP is prepared through a process known as differential centrifugation, in which acceleration force is adjusted to sediment certain cellular constituents based on different specific gravity [33].

Regarding the preparation of PRP, there are 2 techniques:

1. Open technique: the product is exposed to the environment of the working area and comes in contact with different materials that should be used for their production, such as pipettes or product-collection tubes. In the blood processing to obtain PRP with the open technique, it should be guaranteed that the product is not contaminated during microbiological handling.

2. Closed technique: it involves the use of commercial devices with CE marking (including centrifuge equip-
20

Skin Appendage Disord 2018;4:18-24

DOI: $10.1159 / 000477353$
Alves/Grimalt 
ment and application) in which the product is not exposed to the environment (recommended).

Several CE medical devices are available for the production of autologous PRP. Most of them are included in one of the following 3 types of devices:

1. The blood is obtained with a tube that contains an anticoagulant, and this tube can be used for any type of centrifuge.

2. Medical devices with which the blood is collected into a tube that already contains an anticoagulant; the centrifugation can then be made in any type of centrifuge.

3. Medical devices with which the blood is collected into a syringe previously filled with an anticoagulant; usually, the blood is transferred into a secondary device whose shape imposes the use of the centrifuge supplied by the same manufacturer [34].

The preparation of PRP depends on the type of device chosen and should be done according to the manufacturer's instructions (Table 2).

As described in Table 2, there are different PRP systems that facilitate the preparation of PRP in a reproducible manner. All operate on a small volume of drawn blood and on the principle of centrifugation.

Briefly, the procedure requires the use of relatively small volumes of blood. The PRP is obtained from the blood of patients before centrifugation. The whole blood is obtained by venipuncture in anticoagulated tubes (usually with acid citrate dextrose or sodium citrate solution). The blood is then centrifuged with single- or a doublespin centrifugation, depending on the device. The settings of the centrifuge established to obtain PRP at an adjustable concentration are defined by the manufacturer and cannot be changed by the physician.

After centrifugation, the tube shows 3 basic layers: at the bottom of the tube, there are red blood cells with leukocytes deposited immediately above; the middle layer corresponds to the PRP, and at the top, there is the PPP (Fig. 1). The PPP is removed, and PRP is obtained. Platelets can be activated before application of the PRP, although there is no consensus on whether or not platelets must be previously activated before their application and with which agonist [35].

Thrombin and calcium chloride, which are aggregation inducers, are used with the aim to activate platelets and stimulate degranulation, causing the release of the GFs [36].

Some authors activate platelets, whereas others apply platelets without previously activating them, arguing that better results are obtained. Recent studies found that the use of such aggregators is not necessary because at the

Platelet-Rich Plasma: A Review
Table 1. Main functions of the growth factors present in plateletrich plasma

\begin{tabular}{|c|c|}
\hline Growth factors & Main functions \\
\hline PDGF [27] & $\begin{array}{l}\text { - Increases hair growth } \\
\text { - Vascularization } \\
\text { - Angiogenesis stimulator }\end{array}$ \\
\hline TGF- $\beta$ [29] & $\begin{array}{l}\text { - Inhibits hair growth in vitro } \\
\text { - Hair-cell proliferation and regeneration }\end{array}$ \\
\hline VEGF [28] & $\begin{array}{l}\text { - Expressed in DP cells in the anagen phase } \\
\text { - Probably regulates } \\
\text { perifollicular angiogenesis } \\
\text { - Increases perifollicular vessel size during } \\
\text { the anagen growth phase }\end{array}$ \\
\hline EGF $[29,43]$ & $\begin{array}{l}\text { - Angiogenesis stimulator } \\
\text { - Hair-cell proliferation and regeneration }\end{array}$ \\
\hline HGF [36] & - Angiogenesis stimulator \\
\hline FGF $[29,43-45]$ & $\begin{array}{l}\text { - Increases hair growth by inducing the } \\
\text { anagen phase of HF } \\
\text { - Promotes DP cell proliferation } \\
\text { - Increases the HF size in mice } \\
\text { - Angiogenesis stimulators }\end{array}$ \\
\hline IGF-1 $[6,27,46]$ & $\begin{array}{l}\text { - Increases hair growth } \\
\text { - Maintains HF growth in vitro } \\
\text { - Angiogenesis stimulator }\end{array}$ \\
\hline
\end{tabular}

PDGF, platelet-derived growth factor; TGF, transforming growth factor; VEGF, vascular endothelial growth factor; DP, dermal papilla; EGF, epidermal growth factor; HGF, hepatocyte growth factor; FGF, fibroblast growth factor; IGF-1, insulin-like growth factor 1; HF, human follicle(s).

time of administration, the platelets are automatically released and ready to exert their function.

Even though most devices aim to obtain the best PRP, the systems differ extensively in their ability to collect and concentrate platelets depending on the method and time of its centrifugation. As a result, suspensions of different concentrations of platelets and leucocytes are obtained. It is difficult to assess which kit for PRP preparation is better and which is worse [33]. In addition, each preparation may produce different types of PRP with different applications. There is no consensus about the number of centrifugations required, nor on their speed duration.

There is intensive ongoing debate regarding the ideal volume of PRP to administer, the frequency of application, the exact site of administration of PRP, and which technique/preparation system of manufacture to use.

Skin Appendage Disord 2018;4:18-24 21 
Table 2. Blood collection and centrifugation protocols from different medical devices to obtain platelet-rich plasma

\begin{tabular}{|c|c|c|c|c|}
\hline \multirow[t]{2}{*}{ Devices } & \multirow{2}{*}{$\begin{array}{l}\text { Blood collection/ } \\
\text { anticoagulant }\end{array}$} & \multicolumn{3}{|l|}{ Centrifugation } \\
\hline & & number of times & speed/time & centrifuge \\
\hline Selphyl ${ }^{\circledR}$ & Tube $9 \mathrm{~mL} /$ sodium citrate & 1 & $1,100 \mathrm{~g} / 6 \mathrm{~min}$ & Classic \\
\hline PRGF Endoret ${ }^{\circledR}$ & Tube $9 \mathrm{~mL} /$ sodium citrate & 1 & $270 \mathrm{~g} / 7 \mathrm{~min}$ & Classic \\
\hline Cascade $^{(R)}$ & Tube $9 \mathrm{~mL} /$ sodium citrate & 2 & $\begin{array}{l}1,100 \mathrm{~g} / 6 \mathrm{~min} \\
1,450 \mathrm{~g} / 15 \mathrm{~min}\end{array}$ & Classic \\
\hline Plateltex $^{\circledR}$ & Tube $9 \mathrm{~mL} / \mathrm{ACD}$ & 2 & $\begin{array}{l}180 \mathrm{~g} / 10 \mathrm{~min} \\
1,000 \mathrm{~g} / 10 \mathrm{~min}\end{array}$ & Classic \\
\hline Regenkit $^{(\circledR)}$ & Tube $9 \mathrm{~mL} /$ sodium citrate & 1 & $1,500 \mathrm{~g} / 9 \mathrm{~min}$ & Classic \\
\hline ACP Arthrex ${ }^{(R)}$ & $\begin{array}{l}\text { Syringe } 15 \mathrm{~mL} / \mathrm{ACD} \text { or no } \\
\text { anticoagulant }\end{array}$ & 1 & $1,500 \mathrm{rpm} / 5 \mathrm{~min}$ & Adapted \\
\hline$\overline{\text { GPS III }}{ }^{(R)}$ & Syringe 30 or $60 \mathrm{~mL} / \mathrm{ACD}$ & 1 & $3,200 \mathrm{rpm} / 15 \mathrm{~min}$ & Adapted \\
\hline Genesis $^{(B)}$ & Syringe $12 \mathrm{~mL} / \mathrm{ACD}$ & 1 & $2,400 \mathrm{rpm} / 12 \mathrm{~min}$ & Adapted \\
\hline SmartPrep $2^{\circledR}$ & Syringe 20 or $60 \mathrm{~mL} / \mathrm{ACD}$ & 2 & $\begin{array}{l}2,500 \mathrm{rpm} / 4 \mathrm{~min} \\
2,300 \mathrm{rpm} / 10 \mathrm{~min}\end{array}$ & Adapted \\
\hline Proteal $^{\circledR}$ & Syringe $20 \mathrm{~mL} /$ sodium citrate & 1 & $1,800 \mathrm{rpm} / 8 \mathrm{~min}$ & Adapted \\
\hline Magellan $^{(R)}$ & Syringe $30-60 \mathrm{~mL} / \mathrm{ACD}$ & - & - & Adapted device \\
\hline Angel $^{\circledR}$ & Syringe $40-180 \mathrm{~mL} / \mathrm{ACD}$ & - & - & Adapted device \\
\hline
\end{tabular}

ACD, acid citrate dextrose. Courtesy of Dr. Jeremy Magalon, adapted from Dohan Ehrenfest [38].

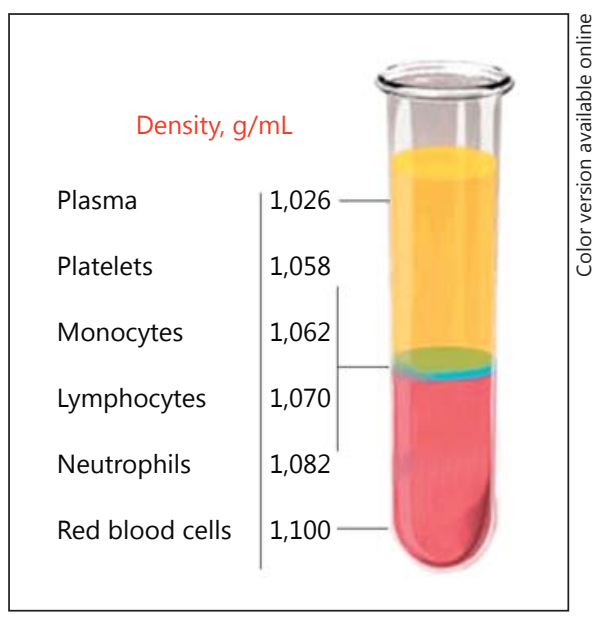

Fig. 1. After centrifugation, the blood components (red blood cells, leukocytes, and platelets) are separated from the plasma due to their different densities. The platelets have the lowest density. Adapted from Dohan Ehrenfest et al. [38].

\section{Classification}

Several authors have tried to characterize and classify the numerous techniques available on the market in terms of preparation (centrifugation speed and use of antico- agulant), content (platelets, leucocytes, and GFs), and applications [36].

Although the literature about PRPs developed with all these contradictions, the need for a standardized terminology is of great importance [36, 37]. Thus, some classifications have been proposed to achieve a consensus terminology in the field of platelet concentrates [3742].

Characterizing the type of PRP used (as a pure PRP in our study) will lead to a better understanding of PRP, and data available will be easier to sort and interpret. Furthermore, this terminology would serve as a basis for further research on the topic.

In 2009, Dohan Ehrenfest et al. [38] proposed a classification of 4 main families of preparations following 2 principle parameters: presence or absence of a cell content (such as leucocytes) and the fibrin architecture:

1. Pure PRP or leucocyte-poor PRP: the preparation obtained is without leucocytes and shows a low-density fibrin network after activation.

2. Leucocyte and PRP: the preparations contain leucocytes and show a low-density fibrin network after activation.

3. Pure PRF or leucocyte-poor PRF: preparations are without leucocytes and with a high-density fibrin network. Unlike pure PRP or PRP containing leukocytes,
Alves/Grimalt 
these products cannot be injected and exist in an activated gel form.

4. Leucocyte-rich fibrin and PRF: products are preparations with leucocytes and with a high-density fibrin network.

Mishra et al. [40] proposed another classification based on the presence or absence of white blood cells, activation status, and platelet concentration, based on the coefficients of an increase in the platelet and leukocyte concentration in PRP compared to the whole-blood baseline, as well as on PRP activation [41].

The classifications were not consensual and there is still the intent to search a classification for PRP that could characterize the injected PRP in order to compare the efficacy of different studies.

An important point of discussion is that in the previous classifications, the authors did not take into account the final volume of the preparation, the presence or $a b$ sence of red blood cells (RBCs) in PRP, and the doses of platelets in the final volume of PRP obtained.

In 2016, Magalon et al. [41] proposed the DEPA classification (Dose, Efficiency, Purity, Activation) that focuses on the quantity of platelets obtained by the PRP kits as well as on product purity and on platelet activation prior to injection.

The DEPA classification is based on 4 different components:

1. Dose of injected platelets: calculated by multiplying the platelet concentration in PRP by the obtained volume of PRP. According to the injected dose (measured in billions or millions of platelets), it should be categorized into (a) very high dose of injected platelets of $>5$ billion; (b) high dose of injected platelets, from 3 to 5 billion; (c) medium dose of injected platelets, from 1 to 3 billion, and (d) low dose of injected platelets, $<1$ billion.

2. Efficiency of the production: corresponds to the percentage of platelets recovered in the PRP from the blood. It is categorized as follows: (a) high device efficiency, if the recovery rate in platelets is $>90 \%$; (b) medium device efficiency, if the recovery rate in platelets is between 70 and $90 \%$; (c) low device efficiency, if the recovery rate is between 30 and $70 \%$, and (d) poor device efficiency, if the recovery rate is $<30 \%$ and corresponds to the relative composition of platelets, leucocytes, and RBCs in the obtained PRP.

3. Purity of the PRP obtained: correlates to the relative composition of platelets, leucocytes, and RBCs in the obtained PRP. It is described as (a) very pure PRP, if the percentage of platelets in the PRP, compared with RBCs and leucocytes, is $>90 \%$; (b) pure PRP, between
70 and $90 \%$ of the platelets; (c) heterogeneous PRP, if the percentage of platelets is between 30 and $70 \%$, and (d) whole-blood PRP, if the percentage of platelets in the PRP is $<30 \%$ compared with RBCs and leucocytes. 4. Activation process: if an exogenous clotting factor was used to activate platelets, such as autologous thrombin or calcium chloride.

Although this last classification is very complete, this quantification cannot be defined by the physician and should be registered in each CE medical device available for preparation of PRP.

\section{Conclusion}

PRP is being used as a new therapeutic option for different pathologies in the field of dermatology, such as trichology, wound healing, and cosmetic medicine. In this manner, understanding the biology and mechanism of action of this therapy should help clinicians in selecting a system that meets their specific needs for a given indication. In addition, characterizing the type of PRP used will lead to a standardization of PRP, making it easier to sort and interpret available data. We hope that this review serves as a basis for further research on the use of PRP.

\section{Disclosure Statement}

All authors have no conflicts of interest to disclose.

References

Skin Appendage Disord 2018;4:18-24 DOI: 10.1159/000477353
1 Andia I, Abate M: Platelet rich plasma: underlying biology and clinical correlates. Regen Med 2013;8:645-658.

2 Andia I: Platelet-rich plasma biology; in Alves R, Grimalt R (eds): Clinical Indications and Treatment Protocols with Platelet-Rich Plasma in Dermatology. Barcelona, Ediciones Mayo, 2016, pp 3-15.

3 Conde Montero E, Fernández Santos ME, Suárez Fernández R: Platelet-rich plasma: applications in dermatology. Actas Dermosifiliogr 2015;106:104-111.

4 Lynch MD, Bashir S: Applications of plateletrich plasma in dermatology: a critical appraisal of the literature. J Dermatolog Treat 2016; 27:285-289.

5 Andia E, Rubio-Azpeitia J, Martin I, Abate M: Current concepts and translational uses of platelet rich plasma biotechnology; in Ekinci D (ed.): Biotechnology. InTech, 2015, DOI: 10.5772/59954. https://www.intechopen. com/books/biotechnology/current-concepts-and-translational-uses-of-plateletrich-plasma-biotechnology.

Platelet-Rich Plasma: A Review

DOI. $10.1159 / 000477353$ 
6 Li ZJ, Choi HI, Choi DK, Sohn KC, Im M, Seo YJ, Lee YH, et al: Autologous platelet-rich plasma: a potential therapeutic tool for promoting hair growth. Dermatol Surg 2012;38: 1040-1046.

7 Sommeling CE, Heyneman A, Hoeksema H, Verbelen J, Stillaert FB, Monstrey S: The use of platelet-rich plasma in plastic surgery: a systematic review. J Plast Reconstr Aesthet Surg 2013;66:301-311.

8 Salazar-Álvarez AE, Riera-del-Moral LF, García-Arranz M, Alvarez-García J, ConcepciónRodriguez NA, Riera-de-Cubas L: Use of platelet-rich plasma in the healing of chronic ulcers of the lower extremity. Actas Dermosifiliogr 2014;105:597-604.

9 Picard F, Hersant B, Bosc R, Meningaud JP: Should we use platelet-rich plasma as an adjunct therapy to treat "acute wounds", "burns", and "laser therapies": a review and a proposal of a quality criteria checklist for further studies. Wound Repair Regen 2015;23: 163-170.

10 Cobos R, Aizpuru F, Parraza N, Anitua E, Orive G: Effectiveness and efficiency of platelet rich plasma in the treatment of diabetic ulcers. Curr Pharm Biotechnol 2015;16:630634.

11 Sclafani AP, Azzi J: Platelet preparations for use in facial rejuvenation and wound healing: a critical review of current literature. Aesthec Plast Surg 2015;39:495-505.

12 Conde Montero E: PRP in wound healing; in Alves R, Grimalt R (eds): Clinical Indications and Treatment Protocols with Platelet-Rich Plasma in Dermatology. Barcelona, Ediciones Mayo, 2016, pp 59-72.

$13 \mathrm{Kim}$ DH, Je YJ, Kim CD, Lee YH, Seo YJ, Lee JH, Lee Y: Can platelet-rich plasma be used for skin rejuvenation? Evaluation of effects of platelet-rich plasma on human dermal fibroblast. Ann Dermatol 2011;23:424-431.

14 Sclafani AP, McCormick SA: Induction of dermal collagenesis, angiogenesis, and adipogenesis in human skin by injection of platelet-rich fibrin matrix. Arch Facial Plast Surg 2012;14:132-136.

15 Lola Bou Camps: PRP in cosmetic dermatology; in Alves R, Grimalt R (eds): Clinical Indications and Treatment Protocols with Platelet-Rich Plasma in Dermatology. Barcelona, Ediciones Mayo, 2016, pp 45-57.

16 Girão L: PRP and other applications in dermatology; in Alves R, Grimalt R (eds): Clinical Indications and Treatment Protocols with Platelet-Rich Plasma in Dermatology. Barcelona, Ediciones Mayo, 2016, pp 73-78.

17 Giordano S, Romeo M, Lankinen P: Plateletrich plasma for androgenetic alopecia: does it work? Evidence from meta analysis. J Cosmet Dermatol 2017, Epub ahead of print.

18 Ayatollahi A, Hosseini H, Gholami J, Mirminachi B, Firooz F, Firooz A: Platelet rich plasma for treatment of non-scarring hair loss: systematic review of literature. J Dermatolog Treat 2017, Epub ahead of print.
19 Theml H: Physiology and pathophysiology of blood cells; in Theml H, Diem H, Haferlach T (eds): Color Atlas of Hematology. Stuttgart, Thieme, 2004.

20 Harmon K, Hanson R, Bowen J, Greenberg S, Magaziner E, Vandenbosch J, et al: Guidelines for the use of platelet rich plasma. https:// www.scribd.com/document/159334949/206ICMS-Guidelines-for-the-Use-of-PlateletRich-Plasma-Draftob-oasbonasdandbowndoww.

21 Ferrando J, Fernández-Sartorio C, González de Cossío AC, Navarra E: Tratamiento de la alopecia androgenetica con factores de crecimiento plaquetario. Monografías Dermatología 2016;42:491-497.

22 Alves R, Grimalt R: A randomized placebocontrolled, double-blind, half-head study to assess the efficacy of platelet-rich plasma on the treatment of androgenetic alopecia. Dermatol Surg 2016;42:491-497.

23 Wroblewski AP, Melia HJ, Wright VJ: Application of platelet-rich plasma to enhance tissue repair. Oper Tech Orthop 2010;20:98105.

24 Graziani F, Ivanovski S, Cei S, Ducci F, Tonetti M, Gabriele M: The in vitro effect of different PRP concentrations on osteoblasts and fibroblasts. Clin Oral Implants Res 2006;17: 212-219.

25 Gupta AK, Carviel J: A mechanistic model of platelet-rich plasma treatment for androgenetic alopecia. Dermatol Surg 2016;42:13351339.

26 Uebel CO, da Silva JB, Cantarelli D, Martins $\mathrm{P}$ : The role of platelet plasma growth factors in male pattern baldness surgery. Plast Reconstr Surg 2006;118:1458-1466.

27 Takikawa M, Nakamura S, Nakamura S, Ishirara M, Kishimoto S, Sasaki K: Enhanced effect of platelet-rich plasma containing a new carrier on hair growth. Dermatol Surg 2011; 37:1721-1729.

28 Paus R: Do we need hair follicle stem cells, hair follicle neogenesis to cure common hair loss disorders? Hair Transplant Forum Int 2008;18:89-90.

29 Lin WH, Xiang LJ, Shi HX, Zhang J, Jiang LP, Cai PT, et al. Fibroblast growth factors stimulate hair growth through $\beta$-catenin and Shh expression in C57BL/6 mice. Biomed Res Int 2015;2015:73017.

30 Jain R, De-Eknamkul W: Potential targets in the discovery of new hair growth promoters for androgenic alopecia. Expert Opin Ther Targets 2014;18:787-806.

31 Akiyama M, Smith LT, Holbrook KA: Growth factor and growth factor receptor localization in the hair follicle bulge and associated tissue in human fetus. J Invest Dermatol 1996;106: 391-396.

32 Myung PS, Takeo M, Ito M, Atit RP: Epithelial Wnt ligand secretion is required for adult hair follicle growth and regeneration. J Invest Dermatol 2013;133:31-41.
33 Dhurat R, Sukesh M: Principles and methods of preparation of platelet-rich Plasma: a review and author's perspective. J Cutan Aesthet Surg 2014;7:189-197.

34 Magalon J: Medical devices for the production of PRP: main aspects to be considered; in Alves R, Grimalt R (eds): Clinical Indications and Treatment Protocols with Platelet-Rich Plasma in Dermatology. Barcelona, Ediciones Mayo, 2016, pp 17-28.

35 Arshdeep, Kumaran MS: Platelet-rich plasma in dermatology: boon or a bane? Indian J Dermatol Venereol Leprol 2014;80:5-14.

36 Anitua E, Sánchez M, Orive G: The importance of understanding what is platelet-rich growth factor (PRGF) and what is not. J Shoulder Elbow Surg 2011;20:e23-e24.

37 Dohan Ehrenfest DM, Sammartino G, Shibli JA, Wang HL, et al: Guidelines for the publication of articles related to platelet concentrates (platelet-rich plasma - PRP, or plateletrich fibrin - PRF): the international classification of the POSEIDO. POSEIDO 2013;1: $17-27$.

38 Dohan Ehrenfest DM, Rasmusson L, Albrektsson T: Classification of platelet concentrates: from pure platelet-rich plasma $(\mathrm{P}$ PRP) to leucocyte- and platelet-rich fibrin (LPRF). Trends Biotechnol 2009;2:158-167.

39 Dohan Ehrenfest DM, Bielecki T, Mishra A, Borzini P: In search of a consensus terminology in the field of platelet concentrates for surgical use: platelet-rich plasma (PRP), platelet-rich fibrin (PRF), fibrin gel polymerization and leukocytes. Curr Pharm Biotechnol 2012;13:1131-1137.

40 Mishra A, Harmon K, Woodall J, Vieira A Sports medicine applications of platelet rich plasma. Curr Pharm Biotechnol 2012;13: 1185-1195.

41 Magalon J, Chateau AL, Bertrand B, Louis ML, Silvestre A, Giraudo L, et al: DEPA classification: a proposal for standardising PRP use and a retrospective application of available devices. BMJ Open Sport Exerc Med 2016;2:e000060.

42 De Pascale MR, Sommese L, Casamassimi A, Napoli C: Platelet derivatives in regenerative medicine: an update. Transfus Med Rev 2015; 29:52-61.

43 Du Cros DL: Fibroblast growth factor and epidermal growth factor in hair development. J Invest Dermatol 1993;101(1 suppl):106S-113S.

44 Takabayashi Y, Nambu M, Ishihara M, Kuwabara M, Fukuda K, Nakamura S, et al: Enhanced effect of fibroblast growth factor2-containing dalteparin/protamine nanoparticles on hair growth. Clin Cosmet Investig Dermatol 2016;9:127-134.

45 Shi HX, Lin C, Lin BB, Wang ZG, Zhang HY, Wu FZ, et al: The anti-scar effects of basic fibroblast growth factor on the wound repair in vitro and in vivo. PLoS One 2013;8:e59966.

46 Eppley BL, Pietzak WS, Blanton M: Plateletrich plasma: a review of biology and applications in plastic surgery. Plast Reconstr Surg 2006;118:147e-159e. 